ARTICLE

https://doi.org/10.1038/s41467-018-07951-y

\title{
Highly stable and efficient all-inorganic lead-free perovskite solar cells with native-oxide passivation
}

Min Chen (10 " , Ming-Gang Ju (1) 2, Hector F. Garces ${ }^{1}$, Alexander D. Carl ${ }^{3}$, Luis K. Ono ${ }^{4}$, Zafer Hawash (1) ${ }^{4}$, Yi Zhang1, Tianyi Shen', Yabing Qi(D) ${ }^{4}$, Ronald L. Grimm³, Domenico Pacifici (D) ${ }^{1}$, Xiao Cheng Zeng (D) ${ }^{2}$, Yuanyuan Zhou ${ }^{1} \&$ Nitin P. Padture (I) ${ }^{1}$

There has been an urgent need to eliminate toxic lead from the prevailing halide perovskite solar cells (PSCs), but the current lead-free PSCs are still plagued with the critical issues of low efficiency and poor stability. This is primarily due to their inadequate photovoltaic properties and chemical stability. Herein we demonstrate the use of the lead-free, allinorganic cesium tin-germanium triiodide $\left(\left.\mathrm{CsSn}_{0.5} \mathrm{Ge}_{0.5}\right|_{3}\right)$ solid-solution perovskite as the light absorber in PSCs, delivering promising efficiency of up to $7.11 \%$. More importantly, these PSCs show very high stability, with less than $10 \%$ decay in efficiency after $500 \mathrm{~h}$ of continuous operation in $\mathrm{N}_{2}$ atmosphere under one-sun illumination. The key to this striking performance of these PSCs is the formation of a full-coverage, stable native-oxide layer, which fully encapsulates and passivates the perovskite surfaces. The native-oxide passivation approach reported here represents an alternate avenue for boosting the efficiency and stability of lead-free PSCs.

\footnotetext{
${ }^{1}$ School of Engineering, Brown University, Providence, Rhode Island 02912, USA. ${ }^{2}$ Department of Chemistry, University of Nebraska-Lincoln, Lincoln, Nebraska 68588, USA. ${ }^{3}$ Department of Chemistry and Biochemistry, Worcester Polytechnic Institute, Worcester, MA 01609, USA. ${ }^{4}$ Energy Materials and Surface Sciences Unit, Okinawa Institute of Science and Technology Graduate University, Okinawa 904-0495, Japan. Correspondence and requests for materials should be addressed to Y.Z. (email: yuanyuan_zhou@brown.edu) or to N.P.P. (email: nitin_padture@brown.edu)
} 
T he promise of high efficiency and low cost has been propelling perovskite solar cells (PSCs) research over the past decade or $\mathrm{so}^{1-4}$. While the record power conversion efficiency (PCE) of PSCs is now approaching $24 \%{ }^{5}$, rivaling that of silicon-based solar cells, the state-of-the-art PSCs employ leadbased organic-inorganic halide perovskite absorber materials. The toxicity of lead associated with the lifecycle of these PSCs is a serious concern, and it may prove to be a major hurdle in the path toward their commercialization ${ }^{6-9}$. Thus, significant effort is being devoted toward the development of low-cost, efficient leadfree PSCs. Several low-toxicity cations have been proposed for replacing $\mathrm{Pb}(\mathrm{II})$ in halide perovskites, including $\mathrm{Ag}(\mathrm{I})^{10}$, $\mathrm{Bi}(\mathrm{III})^{11,12}, \mathrm{Sb}(\mathrm{III})^{13}, \mathrm{Ti}(\mathrm{IV})^{14,15}, \mathrm{Ge}(\mathrm{II})^{16}$, and $\mathrm{Sn}(\mathrm{II})^{17,18}$. Among these candidates, halide perovskites based on Sn(II) have shown the highest PCE, and, thus, have attracted the most attention in the PSC field. Typical Sn-based halide perovskites that have been studied include $\mathrm{CH}_{3} \mathrm{NH}_{3} \mathrm{SnI}_{3}\left(\mathrm{MASnI}_{3}\right.$ ), $\mathrm{HC}\left(\mathrm{NH}_{2}\right)_{2} \mathrm{SnI}_{3}\left(\mathrm{FASnI}_{3}\right)$, and $\mathrm{CsSnI}_{3}$. While PSCs based on $\mathrm{MASnI}_{3}$ and $\mathrm{FASnI}_{3}$ perovskites have been shown to deliver high PCE, up to $9 \%{ }^{19}$, these materials have intrinsically low stability ${ }^{20,21}$. This is primarily attributed to the presence of the organic cation, which is prone to facile volatilization. In this context, the all-inorganic lead-free $\mathrm{CsSnI}_{3}$ perovskite becomes a more attractive candidate ${ }^{17,22}$. However, the facile oxidation of $\mathrm{Sn}(\mathrm{II})$ to $\mathrm{Sn}(\mathrm{IV})$, and attendant phase instability in the $\mathrm{CsSnI}_{3}$ perovskite, results in the rapid degradation of its properties ${ }^{23}$. The most effective strategy that has been proposed for mitigating this issue is to incorporate $\mathrm{Sn}(\mathrm{II})$-halide additive $\left(\mathrm{SnF}_{2}{ }^{24}, \mathrm{SnCl}_{2}{ }^{25}\right.$, and $\mathrm{SnI}_{2}{ }^{26}$ ), but the resulting PSCs show maximum PCE of only $4.81 \%$, and no operational stability data on these PSCs has been reported. This calls for new stabilization approaches that can boost the stability and PCE of $\mathrm{CsSnI}_{3}$-based PSCs simultaneously.

Herein, we report the surprising discovery that by simply alloying $\mathrm{Ge}(\mathrm{II})$ in $\mathrm{CsSnI}_{3}$ to form a $\mathrm{CsSn}_{0.5} \mathrm{Ge}_{0.5} \mathrm{I}_{3}$ composition perovskite, its thin films can become highly stable and airtolerant. While the favorable Goldschmidt tolerance (0.94) and octahedral (0.4) factors in $\mathrm{CsSn}_{0.5} \mathrm{Ge}_{0.5} \mathrm{I}_{3}$ contribute to the structural stability of this alloy (Supplementary Fig. 1), the extremely high oxidation activity of Ge(II) enables the rapid formation of an ultrathin $(<5 \mathrm{~nm})$ uniform native-oxide surface passivating layer on the $\mathrm{CsSn}_{0.5} \mathrm{Ge}_{0.5} \mathrm{I}_{3}$ perovskite, imparting it with superior stability, even compared with the prototypical $\mathrm{MAPbI}_{3}$ perovskite. We also demonstrate a facile one-step vaporprocessing method for the deposition of $\mathrm{CsSn}_{0.5} \mathrm{Ge}_{0.5} \mathrm{I}_{3}$ perovskite thin films, leading to PSCs with PCE up to $7.11 \%$. We further show that these $\mathrm{CsSn}_{0.5} \mathrm{Ge}_{0.5} \mathrm{I}_{3}$ PSCs are highly stable upon continuous operation under 1-sun illumination for over $500 \mathrm{~h}$. The extraordinary stability of the $\mathrm{CsSn}_{0.5} \mathrm{Ge}_{0.5} \mathrm{I}_{3}$ perovskite is explained using coupled experiments and theory.

\section{Results}

Synthesis and processing of $\mathrm{CsSn}_{0.5} \mathrm{Ge}_{0.5} \mathrm{I}_{3}$ perovskites. Figure 1a is a photograph of $\mathrm{CsSn}_{0.5} \mathrm{Ge}_{0.5} \mathrm{I}_{3}$ perovskite powder synthesized by solid-state reaction (at $450^{\circ} \mathrm{C}$ ) in an evacuated Pyrex glass tube. The indexed X-ray diffraction pattern (XRD) in Supplementary Fig. 1a confirms that this powder is a single-phase perovskite, and it appears to crystallize in the space group of $R 3 \mathrm{~m}$. Its comparison with the XRD pattern of reference $\mathrm{CsGeI}_{3}$ perovskite powder (space group R3m), synthesized using the same procedure, in Supplementary Fig. 1b shows peak shifts to lower $2 \theta$ angles. This indicates an expansion of the unit cell, as expected with the substitution of the smaller Ge(II) by the larger Sn(II). Reference black phase B- $\gamma$-CsSnI 3 perovskite, which was also synthesized using the same procedure, crystallizes in the orthorhombic (space group Pnma) structure; Supplementary Fig. 1c shows its XRD pattern. (More detailed crystallographic analyses of $\mathrm{CsSn}_{1-x} \mathrm{Ge}_{x} \mathrm{I}_{3}$ perovskite alloys will be studied in the future to resolve the symmetry transition with the increase of Ge content.)

The $\mathrm{CsSn}_{0.5} \mathrm{Ge}_{0.5} \mathrm{I}_{3}$ perovskite powder was used to evaporate thin films onto various substrates, as shown schematically in Fig. 1b. Figure $1 \mathrm{c}$ is a photograph of such a film deposited on a $10 \times 10-\mathrm{cm}^{2}$ glass substrate showing dark reddish color. The XRD pattern in Fig. 1d confirms the single-phase nature of the $\mathrm{CsSn}_{0.5} \mathrm{Ge}_{0.5} \mathrm{I}_{3}$ perovskite thin film (on a glass substrate). The inset within Fig. 1d shows scanning electron microscope (SEM) image of the top surface. SEM image of the cross section is presented in Supplementary Fig. 2a, where the typical film thickness is about $200 \mathrm{~nm}$, and the grain size is estimated at about $80 \mathrm{~nm}$. The films appear highly uniform, full-coverage, and ultrasmooth, where the root-mean-square roughness is found to be $2.1 \mathrm{~nm}$, as revealed in the atomic force microscope (AFM) image in Supplementary Fig. 2b.

Figure 1e presents optical absorption and steady-state photoluminescence (PL) spectra of the $\mathrm{CsSn}_{0.5} \mathrm{Ge}_{0.5} \mathrm{I}_{3}$ perovskite thin film. Good absorption is observed across the visible region, with an edge at about $840 \mathrm{~nm}$, although the estimated Urbach energy is relatively high $(37 \mathrm{meV})$, which could be related to the intrinsic Sn vacancies ${ }^{27,28}$. The PL emission peak is centered at about 830 $\mathrm{nm}$, which is consistent with the absorption. The PL peak is relatively sharp (FWHM $52 \mathrm{~nm}$ ), a hallmark of a good lightabsorber material. The PL emission was also mapped over a $50 \times$ $50-\mu \mathrm{m}^{2}$ area at various locations on the thin films (Supplementary Fig. 3), confirming the optical uniformity across the entire film. The Tauc plot of the thin films in Supplementary Fig. 4a indicates an optical bandgap of about $1.50 \mathrm{eV}$, which is consistent with that predicted in our earlier computational studies ${ }^{29}$. This bandgap lies in-between the bandgaps of $\mathrm{CsSnI}_{3}(1.31 \mathrm{eV})$ and $\mathrm{CsGeI}_{3}(1.63 \mathrm{eV})$ perovskites, which is to be expected due to the upshift of the valence band maximum (VBM) with the substitution of $\mathrm{Sn}(\mathrm{II})$ for $\mathrm{Ge}(\mathrm{II})$ in $\mathrm{CsGeI}_{3}$. Supplementary Fig. 4b plots the real and the imaginary parts of the refractive index of the $\mathrm{CsSn}_{0.5} \mathrm{Ge}_{0.5} \mathrm{I}_{3}$ perovskite thin films as a function of the wavelength.

Native-oxide surface passivation in $\mathrm{CsSn}_{0.5} \mathrm{Ge}_{0.5} \mathrm{I}_{3}$ perovskite. As soon as the $\mathrm{CsSn}_{0.5} \mathrm{Ge}_{0.5} \mathrm{I}_{3}$ perovskite thin films are exposed to air, a stable native-oxide layer forms on the surface, within $30 \mathrm{~s}$. Figure 2a plots Ge 3d X-ray photoelectron spectroscopy (XPS) spectra at different incidence angles. At shallow angles, the presence of $\mathrm{Ge}(\mathrm{IV})$ is detected (binding energy $33.0 \mathrm{eV}$ ). Since the surface roughness is about $2.1 \mathrm{~nm}$ and the native-oxide layer is expected to be less than 5-nm thick, the surface layer is sampled primarily at such shallow angles. With increasing incidence angle, the $\mathrm{Ge}(\mathrm{II})$ peak (binding energy $31.0 \mathrm{eV}$ ) dominates, as the underlying $\mathrm{CsSn}_{0.5} \mathrm{Ge}_{0.5} \mathrm{I}_{3}$ perovskite thin film is sampled primarily. These spectra are deconvoluted, and the estimated Ge(II) content (relative to total Ge) is plotted in Fig. 2b. A sharp drop in the $\mathrm{Ge}(\mathrm{II})$ content at incidence angles 30 to $45^{\circ}$ indicates a distinct native-oxide layer comprising Ge(IV) primarily. XPS maps (normal incidence angle) of $\mathrm{Ge} 3 \mathrm{~d}(33.0 \mathrm{eV})$ and $\mathrm{O} 1 \mathrm{~s}(532.0 \mathrm{eV})$ in Fig. $2 c$, d, respectively, of the same surface region show a strong correlation ${ }^{30,31}$, confirming the formation of a $\mathrm{Ge}(\mathrm{IV})$-rich native oxide. Supplementary Fig. 5a plots Sn 3d XPS spectra as a function of incidence angle. Since the binding energies for $\mathrm{Sn}$ (II) $(486.0 \mathrm{eV})$ and $\mathrm{Sn}(\mathrm{IV})(486.6 \mathrm{eV})$ are very close, it is difficult to discern the oxidation state of Sn. Nevertheless, the Sn:Ge atomic ratio is extracted from the data in Supplementary Fig. 5a and Fig. 2a, and it is plotted in Supplementary Fig. 5b as a function of incidence angle. It can be seen that there is a small amount $(<10 \%)$ of Sn present in the native oxide. In a related experiment, 

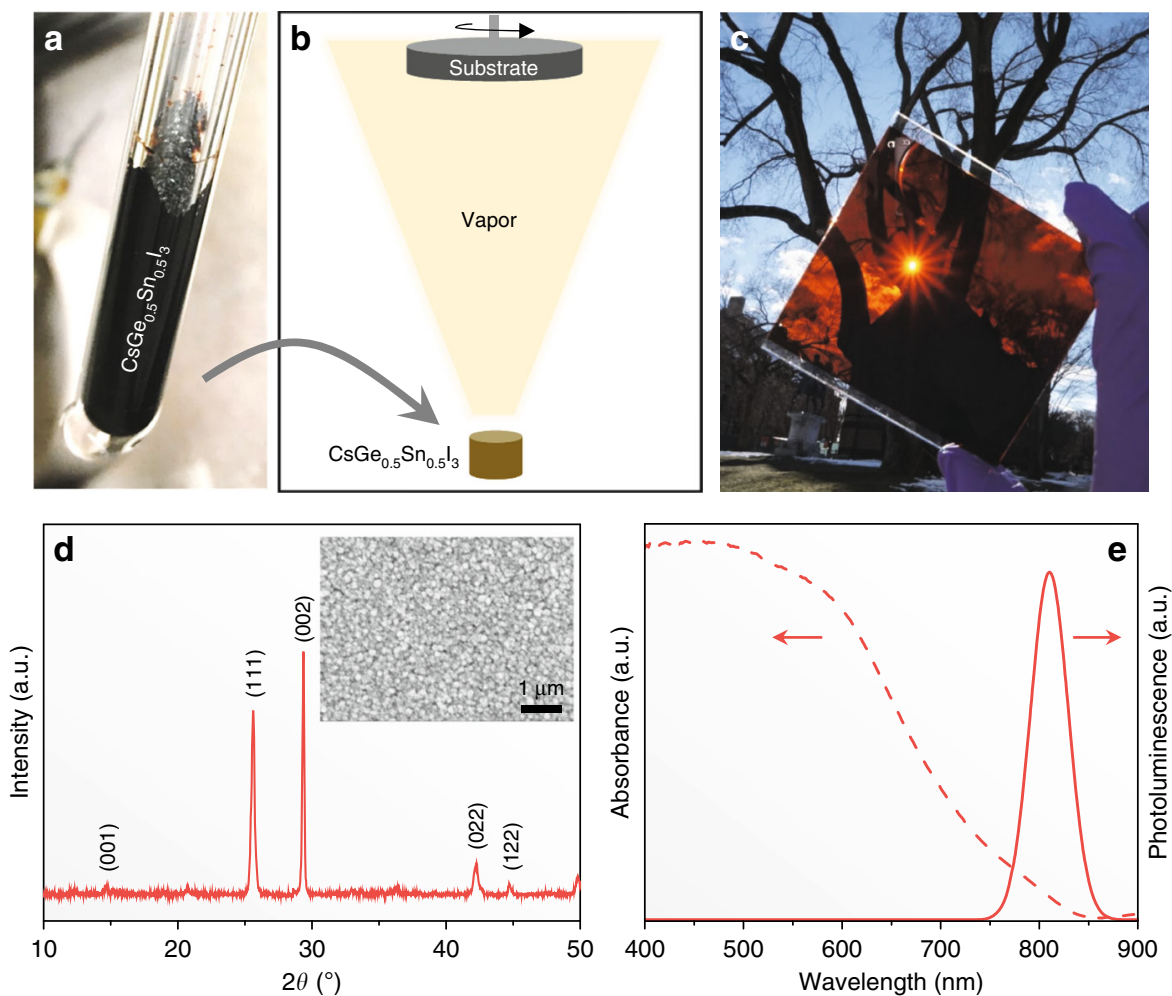

Fig. 1 Film synthesis and characterization. a Photograph of as-synthesized $\mathrm{CsSn}_{0.5} \mathrm{Ge}_{0.5} \mathrm{I}_{3}$ perovskite solid using the melt-crystallization method. b Schematic illustration of the single-source evaporation method for the deposition of ultrasmooth $\mathrm{CsSn}_{0.5} \mathrm{Ge}_{0.5} \mathrm{l}_{3}$ perovskite thin film. c Photograph of an as-synthesized large-area $\mathrm{CsSn}_{0.5} \mathrm{Ge}_{0.5} \mathrm{I}_{3}$ perovskite thin film on a glass substrate showing dark reddish color. $\mathbf{d}$ Indexed XRD pattern of the fresh $\mathrm{CsSn}_{0.5} \mathrm{Ge}_{0.5} \mathrm{I}_{3}$ perovskite thin film (inset: top-view SEM image of the microstructure). e Absorption and steady-state $\mathrm{PL}$ spectra of a fresh $\mathrm{CsSn}_{0.5} \mathrm{Ge}_{0.5} \mathrm{I}_{3}$ perovskite thin film
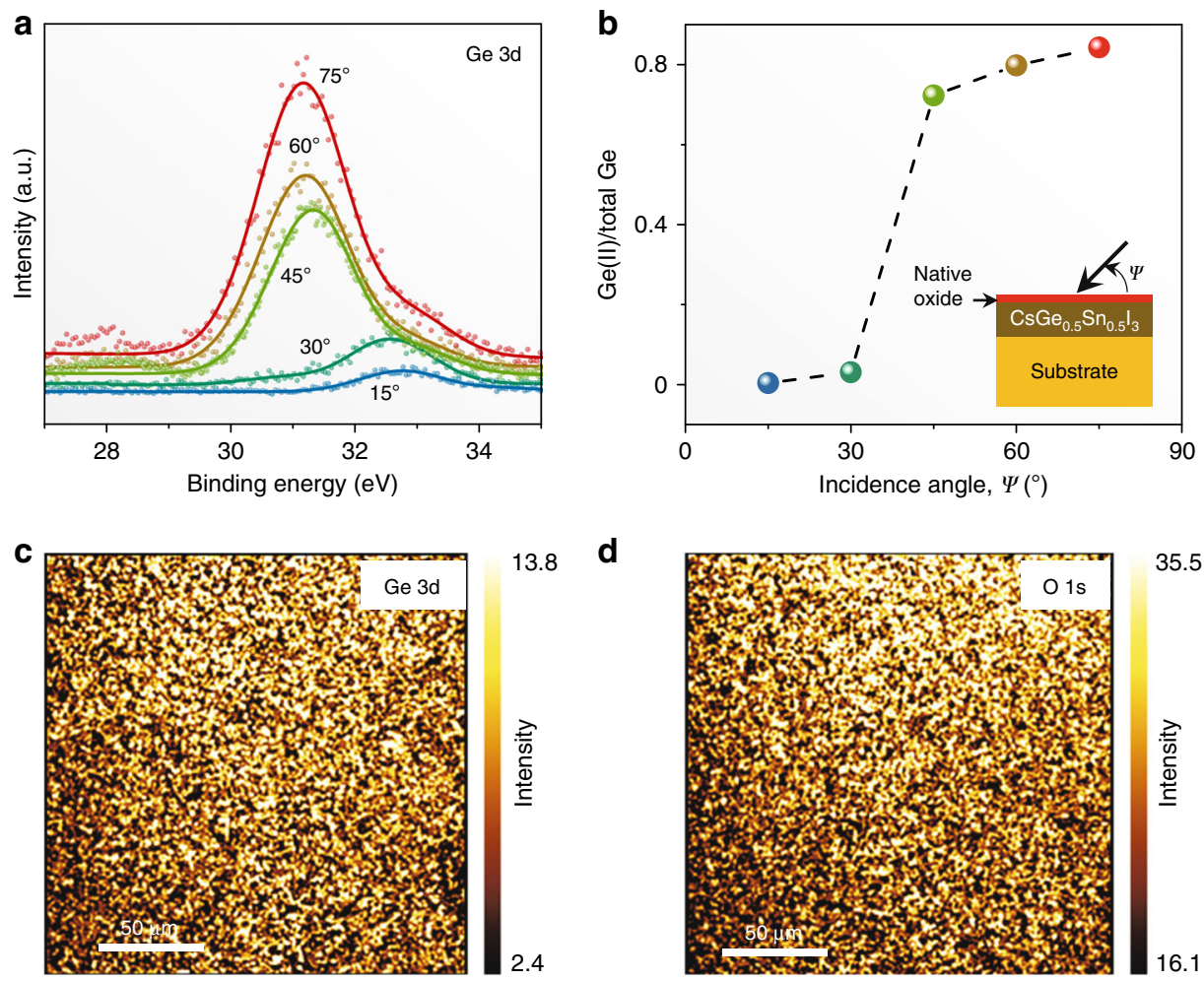

Fig. 2 XPS characterization. a Ge 3d XPS spectra, at different incidence angles, from $\mathrm{CsSn}_{0.5} \mathrm{Ge}_{0.5} \mathrm{l}_{3}$ perovskite thin film that has been exposed to air. b Corresponding plot of the fraction of Ge(II) vs. the incidence angle. c, d XPS maps of Ge $3 \mathrm{~d}(33 \mathrm{eV})$ and O 1s (532 eV), respectively, from the same area of the thin film 

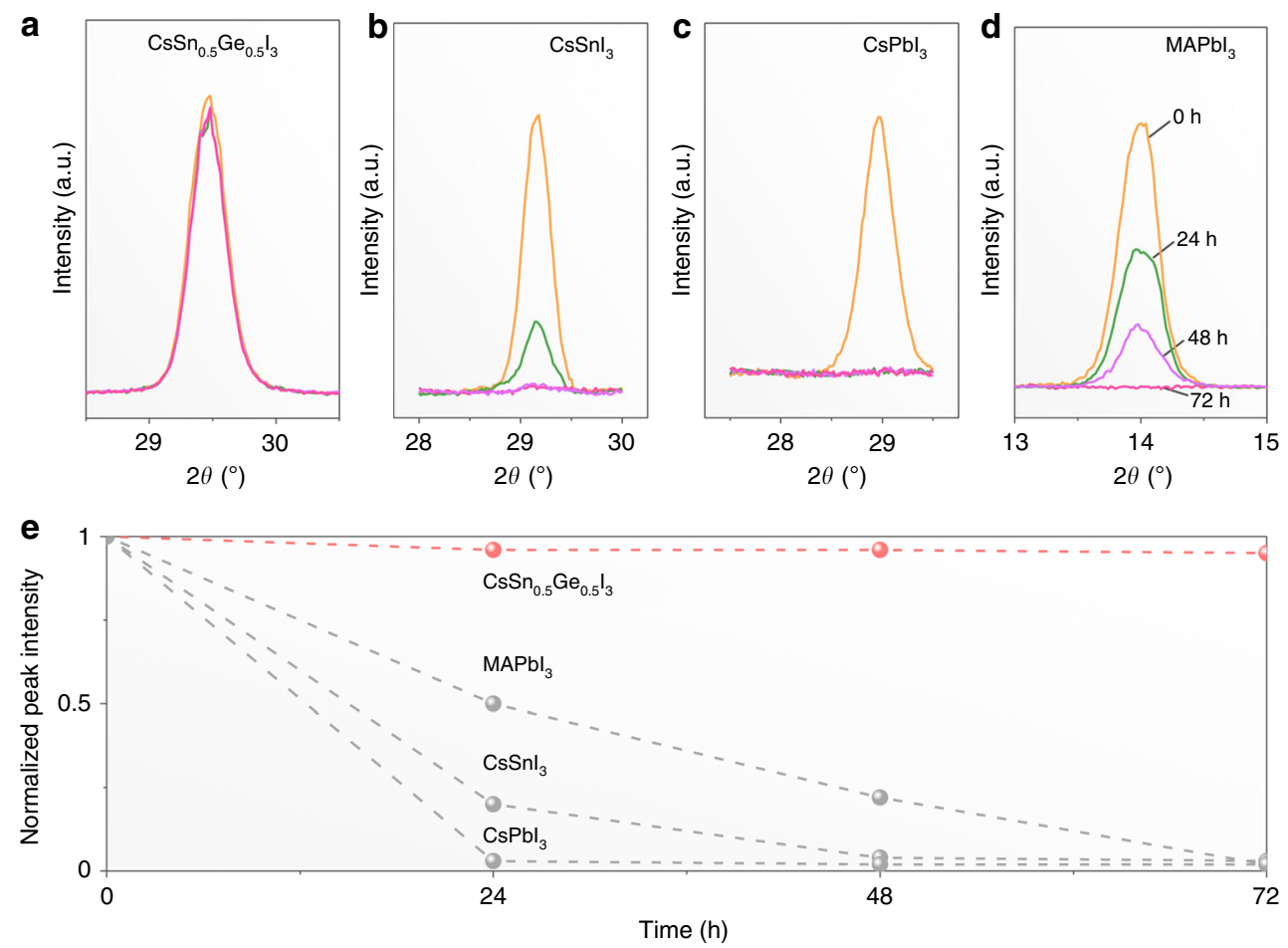

Fig. 3 Thin-film stability. XRD patterns of perovskite thin films before and after exposure for 24,48 , and $72 \mathrm{~h}$ to light-soaking (1 sun) at approximately $45{ }^{\circ} \mathrm{C}$ and $80 \% \mathrm{RH}: \mathbf{a} \mathrm{CsSn}_{0.5} \mathrm{Ge}_{0.5} \mathrm{I}_{3}, \mathbf{b} \mathrm{CsSnl}_{3}, \mathbf{c} \mathrm{CsPbl}_{3}$, and $\mathbf{d} \mathrm{MAPbl}_{3}$. e Plots of relative XRD peak intensities vs. time from a to $\mathbf{d}$

Ar sputtering (15 s) was utilized in situ to remove the nativeoxide layer at the surface. The XPS results $\left(15^{\circ}\right.$ incidence angle) after Ar sputtering (Supplementary Figs. 6a and 6b) show Ge(II)rich and O-lean surface corresponding to the $\mathrm{CsSn}_{0.5} \mathrm{Ge}_{0.5} \mathrm{I}_{3}$ perovskite, which confirms that the thickness of the oxide layer is within $5 \mathrm{~nm}$. Taken together, the XPS results indicate that a uniform layer of $\mathrm{Sn}$-containing $\mathrm{Ge}(\mathrm{IV})$-rich native oxide $(<5 \mathrm{~nm})$ forms on the surface of the $\mathrm{CsSn}_{0.5} \mathrm{Ge}_{0.5} \mathrm{I}_{3}$ perovskite thin films. As with most native-oxide layers that are less than $5 \mathrm{~nm}$ in thickness, this native-oxide layer is expected to be amorphous.

Native oxide passivated $\mathrm{CsSn}_{0.5} \mathrm{Ge}_{0.5} \mathrm{I}_{3}$ perovskite stability. The as-synthesized $\mathrm{CsSn}_{0.5} \mathrm{Ge}_{0.5} \mathrm{I}_{3}$ perovskite powders when exposed to ambient atmosphere $\left(25^{\circ} \mathrm{C}, 80 \% \mathrm{RH}\right)$ for $24 \mathrm{~h}$ remain black and maintain their phase purity (Supplementary Fig. 1d). Moreover, it appears that the $\mathrm{CsSn}_{x} \mathrm{Ge}_{1-x} \mathrm{I}_{3}$ perovskite can become quite stable when the $x$ value is in the range of $0.25-0.75$ (Supplementary Fig. 8). In contrast, reference pure $\mathrm{CsSnI}_{3}$ and $\mathrm{CsGeI}_{3}$ powders turn into yellow non-perovskite phases (Supplementary Fig. If and 1e). These results demonstrate clearly the superior air stability of the alloy $\mathrm{CsSn}_{0.5} \mathrm{Ge}_{0.5} \mathrm{I}_{3}$ perovskite over its pure components. The $\mathrm{CsSn}_{0.5} \mathrm{Ge}_{0.5} \mathrm{I}_{3}$ perovskite thin films subjected to continuous 1-sun illumination in ambient atmosphere $\left(\sim 45^{\circ} \mathrm{C}, 80 \% \mathrm{RH}\right)$ for up to $72 \mathrm{~h}$ are also found to be highly stable. Figure $3 \mathrm{a}$ presents XRD patterns from $\mathrm{CsSn}_{0.5} \mathrm{Ge}_{0.5} \mathrm{I}_{3}$ perovskite thin films exposed for $0,24,48$, and $72 \mathrm{~h}$ showing negligible change. The corresponding relative intensities of the main XRD peak are plotted in Fig. 3e. Comparative experiments on thin films of the popular halide perovskites $\left(\mathrm{CsSnI}_{3}, \mathrm{CsPbI}_{3}\right.$, and $\mathrm{MAPbI}_{3}$ ) show complete degradation after 24,48 , and $72 \mathrm{~h}$, respectively (Fig. 3b-d). Supplementary Fig. 9 presents conductive AFM (c-AFM) images of the $\mathrm{CsSn}_{0.5} \mathrm{Ge}_{0.5} \mathrm{I}_{3}$ perovskite thin film samples exposed to ambient atmosphere for 0,24 , and $48 \mathrm{~h}$, where the microstructure and conductivity appear unchanged at the nanoscale.
Physical properties of $\mathrm{CsSn}_{0.5} \mathrm{Ge}_{0.5} \mathrm{I}_{3}$ perovskite thin films. The time-resolved PL (TRPL) spectroscopy data from $\mathrm{CsSn}_{0.5} \mathrm{Ge}_{0.5} \mathrm{I}_{3}$ perovskite thin films (on glass substrates) in Supplementary Fig. 10a reveal a promising lifetime of $10.92 \mathrm{~ns}$, compared with only 510 ps for the reference $\mathrm{CsSnI}_{3}$ thin film. Supplementary Fig. 10b shows TRPL results for $\mathrm{CsSn}_{0.5} \mathrm{Ge}_{0.5} \mathrm{I}_{3}$ perovskite thin films coated with either phenyl- $\mathrm{C}_{61}$-butyric acid methyl ester: $\mathrm{C}_{60}$ (PCBM: $\mathrm{C}_{60}$ ) or spiro-OMeTAD as electron- or hole-quenching layers, respectively. Based on the PL decay dynamics, the photogenerated carrier diffusion coefficients are estimated at 0.85 $\mathrm{cm}^{2} \mathrm{~s}^{-1}$ and $0.39 \mathrm{~cm}^{2} \mathrm{~s}^{-1}$ for electrons and holes ${ }^{14,32}$, respectively. These correspond to diffusion lengths of $963 \mathrm{~nm}$ and 653 $\mathrm{nm}$ for electrons and holes, respectively, which are sufficiently long for planar thin-film solar cells.

The carrier mobilities in the $\mathrm{CsSn}_{0.5} \mathrm{Ge}_{0.5} \mathrm{I}_{3}$ perovskite thin films were determined by the space-charge-limited-current (SCLC) method using symmetric capacitor-like devices shown schematically in Supplementary Fig. 11a and 11b insets. For determining the electron mobility $\left(\mu_{\mathrm{e}}\right)$ and the hole mobility $\left(\mu_{\mathrm{h}}\right)$ in the dark, the Ga/PCBM: $\mathrm{C}_{60} / \mathrm{CsSn}_{0.5} \mathrm{Ge}_{0.5} \mathrm{I}_{3} / \mathrm{PCBM}: \mathrm{C}_{60} / \mathrm{Ga}$ and the $\mathrm{Au} /$ spiro-OMeTAD/CsSn ${ }_{0.5} \mathrm{Ge}_{0.5} \mathrm{I}_{3} /$ spiro-OMeTAD/Au device structures, respectively, were used, in conjunction with the following equation: ${ }^{33}$

$$
J_{\mathrm{SCL}}=\frac{9 \varepsilon \varepsilon_{0} \mu V^{2}}{8 L^{3}}
$$

Here, $J_{\text {SCL }}$ is the measured current density, $L$ is the film thickness $(=1 \mu \mathrm{m}), \mu$ is the carrier mobility, $\varepsilon$ is the dielectric constant (=28), and $\varepsilon_{\mathrm{o}}$ is the permittivity of free space. The $\mu_{\mathrm{e}}$ and $\mu_{\mathrm{h}}$ are estimated at $974 \mathrm{~cm}^{2} \mathrm{~V}^{-1} \mathrm{~s}^{-1}$ and $213 \mathrm{~cm}^{2} \mathrm{~V}^{-1} \mathrm{~s}^{-1}$, respectively, where the latter is consistent with the $\mu_{\mathrm{h}}$ value of $298 \mathrm{~cm}^{2} \mathrm{~V}^{-1} \mathrm{~s}^{-1}$ determined using the Hall-effect measurements. The electron- and hole-trap densities $\left(n_{\mathrm{t}}\right)$ were calculated using 
a

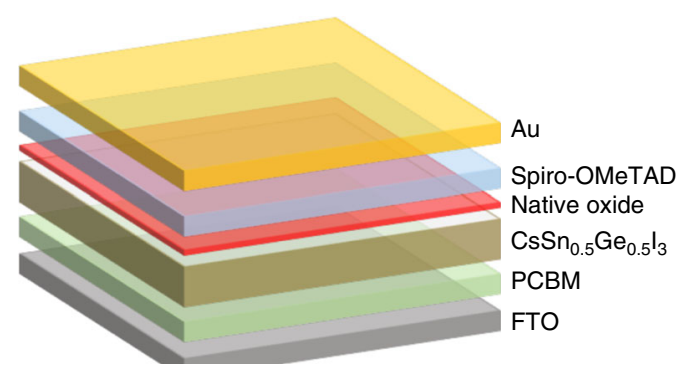

b

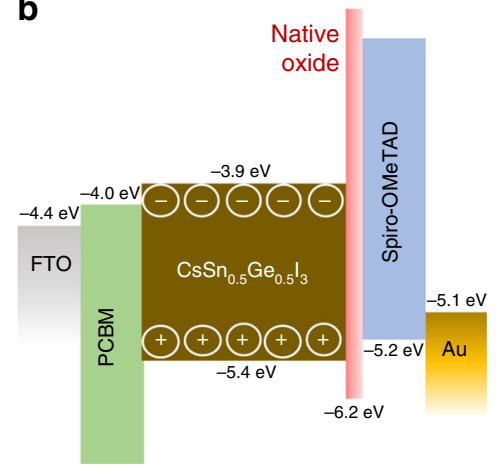

C

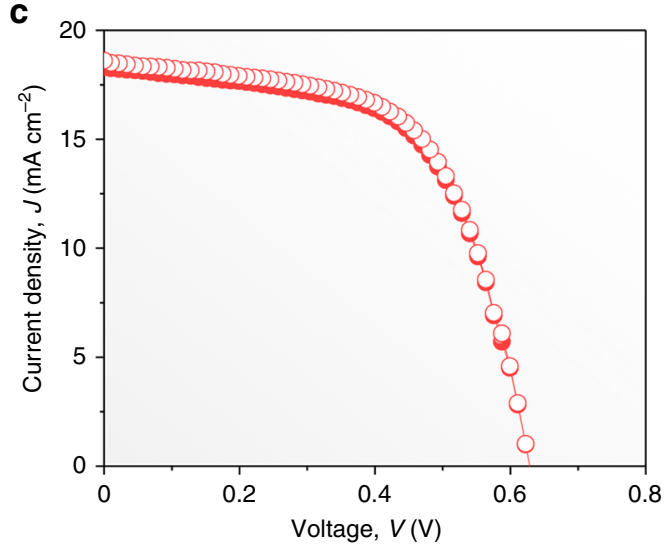

e

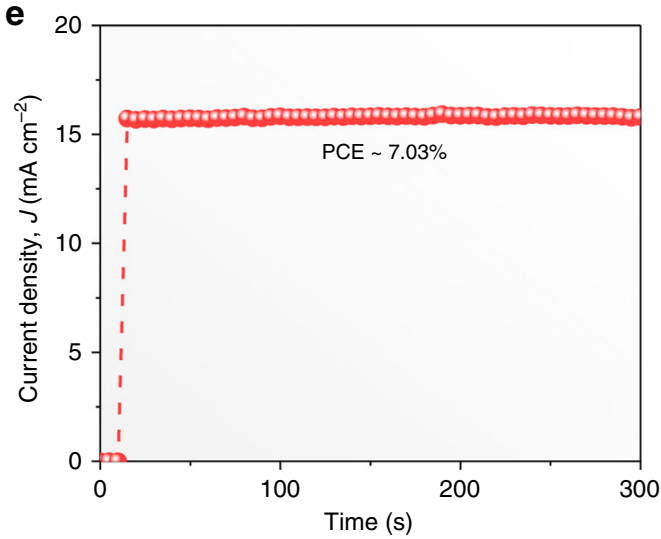

d

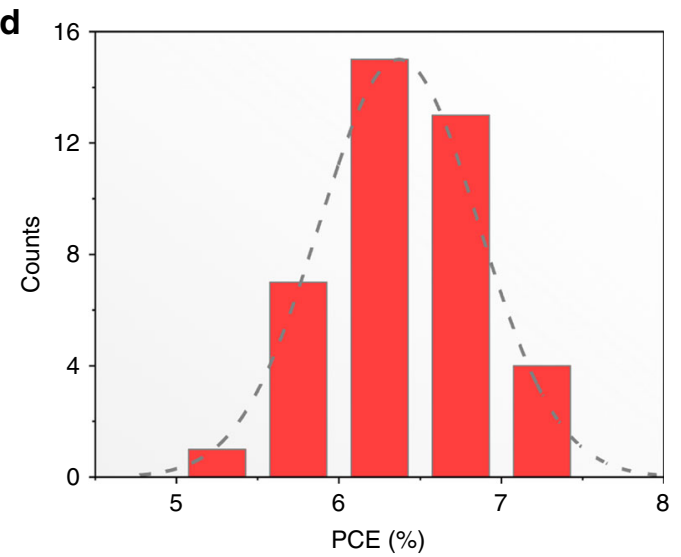

f

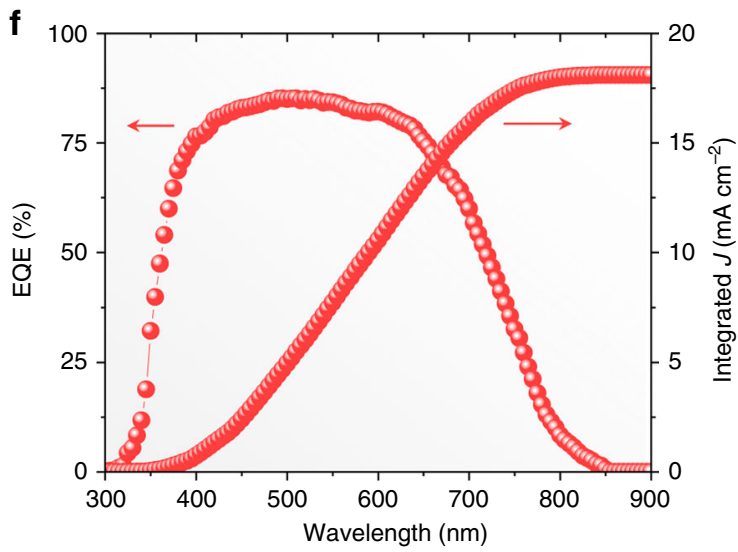

Fig. 4 Device architecture and performance of $\mathrm{CsSn}_{0.5} \mathrm{Ge}_{0.5} \mathrm{I}_{3}$ thin-film PSCs. a Schematic illustration showing the planar PSC device structure used here. b Corresponding energy-level diagram. c J-V responses of the "champion" PSC device. d PCE statistics. e Stabilized power output and $\mathbf{f}$ EQE spectrum of the "champion" PSC device

the following equation: ${ }^{34,35}$

$$
n_{\mathrm{t}}=\frac{V_{\mathrm{TFL}} 2 \varepsilon \varepsilon_{0}}{e L^{2}}
$$

where $V_{\mathrm{TFL}}$ is the trap-filled limit (TFL) voltage from the plots in Supplementary Fig. 11a and 11b; the electron- and hole-trap densities are estimated to be both as low as about $10^{16} \mathrm{~cm}^{-3}$. All of the above results indicate that the properties of $\mathrm{CsSn}_{0.5} \mathrm{Ge}_{0.5} \mathrm{I}_{3}$ perovskite thin films are highly suitable for thin-film planar solar cells.

Native-oxide-passivated $\mathrm{CsSn}_{\mathbf{0 . 5}} \mathrm{Ge}_{\mathbf{0 . 5}} \mathrm{I}_{3}$ perovskite solar cells. The PV performance of $\mathrm{CsSn}_{0.5} \mathrm{Ge}_{0.5} \mathrm{I}_{3}$ perovskite thin films with the native-oxide layer is evaluated by incorporating them into PSC devices of the architecture shown in Fig. 4a. The
$\mathrm{CsSn}_{0.5} \mathrm{Ge}_{0.5} \mathrm{I}_{3}$ perovskite thin film (about 200-nm thickness) is sandwiched between PCBM electron-transport layer (ETL) and spiro-OMeTAD hole-transport layer (HTL), with the thin nativeoxide layer serving as a wide-bandgap interfacial layer between the $\mathrm{CsSn}_{0.5} \mathrm{Ge}_{0.5} \mathrm{I}_{3}$ perovskite thin film and the HTL. FTO and Au are used as the conducting electrodes. Figure $4 \mathrm{~b}$ shows the energy-level diagrams for this device architecture. The VBM and the apparent bandgap of the amorphous native oxide were determined using the ultraviolet photoemission spectroscopy (UPS) results presented in Supplementary Fig. 12. The VBM of the $\mathrm{CsSn}_{0.5} \mathrm{Ge}_{0.5} \mathrm{I}_{3}$ thin film is determined by performing UPS measurement after the removal of the native-oxide layer using $\mathrm{Ar}$ sputtering (Supplementary Fig. 13). Figure 4c plots the current density $(J)$-voltage $(V)$ responses of the "champion" PSC in reverse and forward scans, showing negligible hysteresis. High overall PCE of $7.11 \%$ is achieved with open-circuit voltage $\left(V_{\mathrm{OC}}\right)$ 

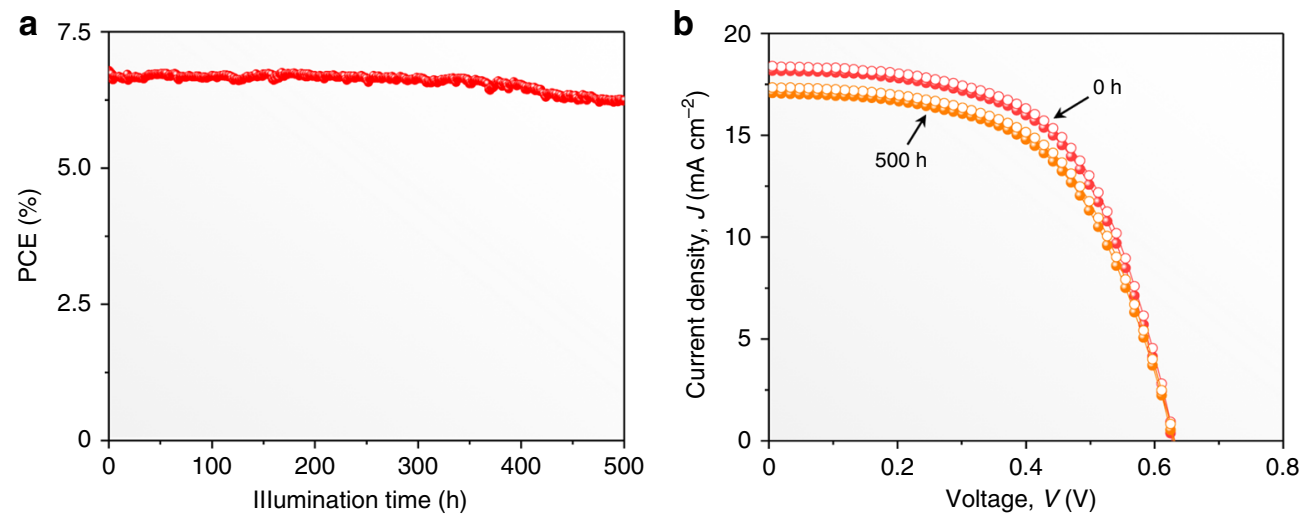

Fig. 5 Device stability of $\mathrm{CsSn}_{0.5} \mathrm{Ge}_{0.5} \mathrm{l}_{3}$ thin-film PSCs. a PCE evolution of a typical unencapsulated PSC in continuous operation under 1-sun illumination at $45^{\circ} \mathrm{C}$ in $\mathrm{N}_{2}$ atmosphere. $\mathbf{b}$ Initial $J-V$ curves (reverse and forward scans) of the PSC and ones at the 500-h mark during continuous operation

of $0.63 \mathrm{~V}$, short-circuit current density $\left(J_{\mathrm{SC}}\right)$ of $18.61 \mathrm{~mA} \mathrm{~cm}^{-2}$, and fill factor (FF) of 0.606 . The $J_{\mathrm{SC}}$ value is consistent with the integrated $J$ of $18.1 \mathrm{~mA} \mathrm{~cm}{ }^{-2}$ from the external quantum efficiency (EQE) spectrum in Fig. 4f. The PCE output at the maximum power point $(0.45 \mathrm{~V})$ shows $7.03 \%$ in Fig. 4 e, which is very close to the extracted PCE from $J-V$ curves. The $V_{\text {OC }}$ reported here is much higher than that in other reported PSCs based on all-inorganic Sn-based halide perovskites ${ }^{26,36}$, and it appears to be stable (Supplementary Fig. 14). The evaluation of PV performance of about 40 PSC devices shows good reproducibility (Fig. 4d), with average PCE of $6.48 \%$. More detailed performance statistics are included in Supplementary Fig. 15, and the device performance parameters are included in Supplementary Table 1.

In order to study the effect of the native-oxide layer on the PSC performance, control PSCs based on $\mathrm{CsSn}_{0.5} \mathrm{Ge}_{0.5} \mathrm{I}_{3}$ perovskite thin films, without the native oxide, were also fabricated. This was accomplished by performing all the processing steps inside a $\mathrm{N}_{2}$ filled glovebox $\left(\mathrm{O}_{2}\right.$ and $\mathrm{H}_{2} \mathrm{O}$ levels below $\left.0.1 \mathrm{ppm}\right)$. Note that the processing of the PSCs described earlier was performed outside of the glovebox. The control PSC shows much lower $V_{\mathrm{OC}}$ of $0.48 \mathrm{~V}$ (reverse scan) and PCE of $3.72 \%$ (Supplementary Fig. 16a). By comparison, a PSC with the native-oxide layer shows significantly higher $V_{\mathrm{OC}}$ of $0.62 \mathrm{~V}$ (reverse scan) and PCE of $6.52 \%$ (Supplementary Fig. 16b). Also, a control PSC based on $\mathrm{CsSnI}_{3}$ perovskite was fabricated using the same evaporation method, showing low PCE of $1.7 \%$ (Supplementary Fig. 17). This clearly demonstrates the advantage of the mixed $\mathrm{CsSn}_{0.5} \mathrm{Ge}_{0.5} \mathrm{I}_{3}$ perovskite composition, and the beneficial effect of the native oxide. The corresponding dark $J-V$ responses are also plotted in Supplementary Figs. 16a and 16b, showing lower current leakage when the native-oxide layer is present.

Long-term device stability. A typical unencapsulated $\mathrm{CsSn}_{0.5} \mathrm{Ge}_{0.5} \mathrm{I}_{3}$ thin-film PSC with 6.79\% PCE (Fig. 5b) was chosen for stability testing where it was operated continuously under continuous 1-sun illumination in $\mathrm{N}_{2}$ atmosphere $\left(45^{\circ} \mathrm{C}\right)$. The continuous monitoring of the $\mathrm{PV}$ performance shows that the PCE has degraded to only $6.23 \%$ (92\% of the initial PCE) after $500 \mathrm{~h}$ of continuous operation (Fig. $5 \mathrm{a}, \mathrm{b}$ ). Figure $5 \mathrm{~b}$ also shows that there is no degradation in the $V_{\mathrm{OC}}$. This demonstrates clearly the excellent operational stability of PSCs based on $\mathrm{CsSn}_{0.5} \mathrm{Ge}_{0.5} \mathrm{I}_{3}$ perovskite thin films with the native-oxide layer. Regarding the stability in air, we have periodically measured the $J-V$ performance of a $\mathrm{CsSn}_{0.5} \mathrm{Ge}_{0.5} \mathrm{I}_{3}$-based PSC that was stored under 1-sun illumination. As shown in Supplementary Fig. 18, after 100-h storage, the PSC promisingly maintains $91 \%$ of the initial PCE. Overall, to the best of our knowledge, such stability is the highest of all lead-free perovskite PSCs reported so far. Note that, while it is practically challenging to perform a direct performance comparison between the $\mathrm{CsSn}_{0.5} \mathrm{Ge}_{0.5} \mathrm{I}_{3}$-based and Pb-based PSCs with the same device configuration, the stability of the $\mathrm{CsSn}_{0.5} \mathrm{Ge}_{0.5} \mathrm{I}_{3}$-based PSCs is reasonably comparable to that of Pb-based PSCs ${ }^{5,37}$.

\section{Discussion}

We have shown that thin-film PSCs based on all-inorganic, $\mathrm{Pb}$ free perovskites of composition $\mathrm{CsSn}_{0.5} \mathrm{Ge}_{0.5} \mathrm{I}_{3}$ show superior performance and exceptional stability. The air stability of $\mathrm{CsSn}_{0.5} \mathrm{Ge}_{0.5} \mathrm{I}_{3}$ perovskite over its pure counterparts $\mathrm{CsSnI}_{3}$ and $\mathrm{CsGeI}_{3}$ is attributed to the formation of the passivating, stable native-oxide layer on $\mathrm{CsSn}_{0.5} \mathrm{Ge}_{0.5} \mathrm{I}_{3}$ perovskite surfaces when exposed to air. As gleaned from the XPS results, the native oxide on $\mathrm{CsSn}_{0.5} \mathrm{Ge}_{0.5} \mathrm{I}_{3}$ perovskite thin films comprises $\mathrm{GeO}_{2}$ doped with a small portion of $\mathrm{Sn}$. It may be that $\mathrm{Sn}$ doping suppresses the formation of those volatile, unstable Ge suboxides during surface passivation in air $^{38,39}$. It is likely that the Sn-doping also enhances the moisture stability of $\mathrm{GeO}_{2}$ itself, making the passivation layer stable in air. Further studies will be performed to understanding the details of Sn-doping effects. Also, as shown in Supplementary Fig. 7, the entropy-of-mixing contributes to $0.03 \mathrm{eV}\left(1.2 k_{\mathrm{B}} T\right.$ at room temperature, $k_{\mathrm{B}}$ is the Boltzmann constant and $T$ is $300 \mathrm{~K}$ ) in reduced free energy in the $\mathrm{CsSn}_{0.5} \mathrm{Ge}_{0.5} \mathrm{I}_{3}$ perovskite, adding to its thermodynamic stability.

It is confirmed that the presence of the native-oxide layer on $\mathrm{CsSn}_{0.5} \mathrm{Ge}_{0.5} \mathrm{I}_{3}$ perovskite thin films is also important for the enhanced PV performance (Supplementary Fig. 16). This can be attributed to the suppression of recombination of photocarriers at the interface between the $\mathrm{CsSn}_{0.5} \mathrm{Ge}_{0.5} \mathrm{I}_{3}$ perovskite and the HTL where the native oxide resides. Also, the dark $J-V$ results in Supplementary Figure 16 indicate improved hole transport across that interface and enhanced shunt resistance, resulting in the enhanced PV performance. The remarkable operational stability of the PV performance is again attributed to the passivating nature of the Sn-containing $\mathrm{GeO}_{2}$ native-oxide layer that protects the thin-film surfaces and interfaces, and also the enhanced intrinsic or thermodynamic stability of the $\mathrm{CsSn}_{0.5} \mathrm{Ge}_{0.5} \mathrm{I}_{3}$ perovskite.

The $\mathrm{CsSn}_{0.5} \mathrm{Ge}_{0.5} \mathrm{I}_{3}$ perovskite composition studied here demonstrates the "proof-of-concept" of the efficacy of the nativeoxide approach in stabilizing materials and devices. Currently, we have relied on the native oxide that forms naturally upon exposure to air, which may not be optimum. Thus, an investigation where the native oxide is tailored via controlled heat treatments (temperature, time, and oxygen partial pressure) is likely to be a 
fruitful research direction. Tuning the electrical and chemical properties of native oxide, and also exploring other ETL, HTL, and electrode materials with energy levels better suited for the cesium tin-germanium triiodide alloy perovskites, may result in PSCs with further enhanced performance. Finally, the nativeoxide approach demonstrated for achieving enhanced PV performance and operational stability could be extended rationally to other halide-perovskite compositions.

\section{Methods}

Synthesis of $\mathrm{CsSn}_{0.5} \mathrm{Ge}_{0.5} \mathrm{I}_{3}$ raw powders and films. All raw materials were purchased from Sigma Aldrich (USA) and used without further purification. $\mathrm{CsSn}_{0.5} \mathrm{Ge}_{0.5} \mathrm{I}_{3}$ perovskite powder was synthesized by solid-state reaction between mixed solid powder precursors CsI:SnI $2: \mathrm{GeI}_{2}$ (2:1:1 molar ratio) carried out in evacuated Pyrex tubes. The tubes were evacuated to $10^{-3}$ Torr pressure for at least 6 $\mathrm{h}$ before sealing them using an oxy-methane torch under vacuum. The evacuated tubes with the powder mixture were then placed in a tube furnace and heated to $450^{\circ} \mathrm{C}$ and held for $72 \mathrm{~h}$, followed by slow cooling at a rate of $20^{\circ} \mathrm{C} \mathrm{h}^{-1}$ to room temperature. The as-synthesized $\mathrm{CsSn}_{0.5} \mathrm{Ge}_{0.5} \mathrm{I}_{3}$ perovskite powder was evaporated to deposit thin films of the same composition on various substrates using a thermal evaporator (Edwards/306A; UK). The deposition was carried out at $10^{-5}$ Torr under low current settings of 36 to $42 \mathrm{~mA}$.

Materials characterization. XRD of the $\mathrm{CsSn}_{0.5} \mathrm{Ge}_{0.5} \mathrm{I}_{3}$ perovskite powders and thin films (on glass substrate) was performed using a high-resolution diffractometer (D8 Advance, Bruker; Germany) with $\mathrm{CuK}_{\mathrm{\alpha}}$ radiation. UV-vis spectra were obtained using a spectrophotometer (UV-2600, Shimadzu; Japan). The microstructures of the thin films were observed using a SEM (LEO 1530VP, Carl Zeiss; Germany). Hall-effect measurements were conducted on a device with fourGa electrode system (2400 SourceMeter, Keithley; USA). The majority carrier was determined to be holes based on the Hall-voltage sign. An XPS and UPS system (5600, PHI; USA) was used to acquire both angle-dependent XPS and UPS spectra. The analysis chamber base pressure was $<10^{-9}$ Torr prior to analysis. The instrument utilized a monochromated $\mathrm{Al}-\mathrm{K}_{\alpha}$ source for X-ray radiation at 1486.7 $\mathrm{eV}$, and a UVS 40A2 (PREVAC, Poland) UV source and UV40A power supply provided by He $1_{\alpha}$ for UPS at $21.22 \mathrm{eV}$. Chamber pressure for UPS was maintained at less than $3 \times 10^{-8}$ Torr. XPS data were collected at different incidence angles. In some cases, in situ Ar sputtering (15 s) was used to etch away the surface layer. XPS mapping was performed on another XPS system (AXIS ULTRA HAS, Kratos Analytical; UK). The determination for the ratio of valence states and atom ratios was performed by Casa XPS (2.3.19) and Origin. The measurement conditions were $150 \mathrm{~W}$ of applied power to the X-ray source under ultrahigh vacuum $\left(10^{-9}\right.$ Torr $)$. The images were collected using field of view $\left(200 \times 200 \mu \mathrm{m}^{2}\right)$ with the high-resolution imaging Iris $(<3 \mu \mathrm{m})$. The binding energies of the elements of interest for generating the maps were first defined by acquiring the XPS spectra. Acquisition time for each elemental mapping was 2 min. The SCLC $I-V$ curves were measured using the 2400 SourceMeter (Keithley; USA). Thicker films $(1 \mu \mathrm{m})$ are used here to eliminate current leakage. However, it should be noted that thicker films may amplify the mobility and lower the trap density. The refractive indices of the $\mathrm{CsSn}_{0.5} \mathrm{Ge}_{0.5} \mathrm{I}_{3}$ perovskite thin films were measured using an ellipsometer (M7000 , J.A. Woollam; USA) at an incidence angle of $75^{\circ}$. The dielectric constant $(\varepsilon)$ was accordingly calculated from electrical capacity test. The steady-state and timeresolved PL spectra were recorded using a spectrophotometer (Varian Cary Eclipse Fluorescence, Agilent; USA) operated at 395-nm excitation. The decay rate and lifetime were determined using the three-parameter decay function fitting method.

Device fabrication and testing. Patterned FTO-coated glass (Hartford Glass Co.; USA) substrates were cleaned successively with detergent solution, acetone, and isopropanol, and they were UV-ozone treated for $20 \mathrm{~min}$ prior to the deposition of the other layers. A less than $20-\mathrm{nm}$ PCBM layer using a $20 \mathrm{mg} \mathrm{mL}^{-1}$ solution of PCBM in 1,2-dichlorobenzene was spin-coated (3000 rpm, 60 s). CsSn ${ }_{0.5} \mathrm{Ge}_{0.5} \mathrm{I}_{3}$ perovskite thin films were then deposited using the method described above. The HTL solution was prepared by dissolving $91 \mathrm{mg}$ of spiro-OMeTAD (Merck, Germany) with additives in $1 \mathrm{~mL}$ of chlorobenzene. The additives were $21 \mu \mathrm{L}$ of Li-bis (trifluoromethanesulfonyl) imide from the stock solution $(520 \mathrm{mg}$ in $1 \mathrm{~mL}$ of acetonitrile), $16 \mu \mathrm{L}$ of FK209 (tris(2-(1H-pyrazol-1-yl)-4-tert-butylpyridine)-cobalt (III) tris(bis(trifluoromethylsulfonyl) imide) $(375 \mathrm{mg}$ in $1 \mathrm{~mL}$ of acetonitrile), and $36 \mu \mathrm{L}$ of 4 -tertbutylpyridine. The HTL solution was spin-coated (4000 rpm, $20 \mathrm{~s}$ ), followed by the deposition of the 80-nm-thick Au electrode by thermal evaporation. Control PSCs were also fabricated, where all the deposition steps were conducted in a $\mathrm{N}_{2}$-filled glovebox $\left(\mathrm{O}_{2}\right.$ and $\mathrm{H}_{2} \mathrm{O}$ levels $\left.<0.1 \mathrm{ppm}\right)$ to prevent the formation of the native oxide on the surface of the $\mathrm{CsSn}_{0.5} \mathrm{Ge}_{0.5} \mathrm{I}_{3}$ perovskite thin films. The $J-V$ characteristics of all the PSCs were measured using the 2400 SourceMeter under simulated 1-sun AM1.5G $100 \mathrm{~mA} \cdot \mathrm{cm}^{-2}$ intensity (Sol3A Class AAA, Oriel, Newport; USA) in ambient atmosphere, using both reverse (from $V_{\mathrm{OC}}$ to $J_{\mathrm{SC}}$ ) and forward (from $J_{\mathrm{SC}}$ to $V_{\mathrm{OC}}$ ) scans with a step size of $0.015 \mathrm{~V}$ and a delay time of $100 \mathrm{~ms}$. The maximum-power output stability of PSCs was measured by monitoring the $J$ output at the maximum power-point bias (deduced from the reverse-scan $J-V$ curves) using the 2400 SourceMeter. A typical active area of 0.1 $\mathrm{cm}^{2}$ was defined using a non-reflective mask for the $J-V$ measurements. The stable output PCE was calculated using the following relation: $\mathrm{PCE}=J\left(\mathrm{~mA} \mathrm{~cm}^{-2}\right) \times V(\mathrm{~V}) /$ $100\left(\mathrm{~mA} \mathrm{~V} \mathrm{~cm}^{-2}\right)$. A shutter was used to control the 1-sun illumination on the PSC. The EQE spectra were obtained using a quantum efficiency measurement system (IQE 200B, Oriel; USA). For long-term device stability test, the PSCs were placed in a holder with a transparent-glass cover and a continuous flow of nitrogen gas. The current/PCE outputs of PSCs at the maximum-power point were monitored under continuous 1-sun-intensity (white-LED) illumination.

DFT calculations. All first-principles computations were performed based on density-functional theory (DFT) methods as implemented in the Vienna ab initio simulation package (VASP 5.4). An energy cutoff of $520 \mathrm{eV}$ was employed, and the atomic positions were optimized using PBEsol functional until the maximum force on each atom was less than $0.02 \mathrm{eV} \cdot \AA^{-1}$. The ion cores were described by using the projector-augmented wave (PAW) method. A $4 \times 4 \times 4 k$-point grid was used for the mixed perovskites. The simulation cells of mixed perovskites with different stoichiometry containing eight units were constructed by replacing the corresponding $\mathrm{Sn}(\mathrm{II})$ or $\mathrm{Ge}(\mathrm{II})$. For each composition, the geometry and cell length were then fully relaxed. This justifies the estimation of the entropy-of-mixing contribution to the free energy by using the analytical formula for ideal alloys: $T \Delta S=-k_{\mathrm{B}} T[x \ln x+(1-x) \ln (1-x)]$. The mixed energy contributions to the free energy can also be estimated based on the formula:

$\Delta E_{\text {mixed }}=E_{\mathrm{CsSn}_{x} \mathrm{Ge}_{(1-x)} \mathrm{I}_{3}}-\left(x E_{\mathrm{CSSnI}_{3}}+(1-x) E_{\mathrm{CsGeI}_{3}}\right)$.

\section{Data availability}

The authors declare that the data related to this study are available upon reasonable request.

Received: 14 August 2018 Accepted: 28 November 2018

Published online: 03 January 2019

\section{References}

1. Kojima, A., Teshima, K., Shirai, Y. \& Miyasaka, T. Organometal halide perovskites as visiblelLight sensitizers for photovoltaic cells. J. Am. Chem. Soc 131, 6050-6051 (2009).

2. Kim, H.-S. et al. Lead iodide perovskite sensitized all-solid-state submicron thin film mesoscopic solar cell with efficiency exceeding 9\%. Sci. Rep. 2, 591 (2012).

3. Lee, M. M., Teuscher, J., Miyasaka, T., Murakami, T. N. \& Snaith, H. J. Efficient hybrid solar cells based on meso-superstructured organometal halide perovskites. Science 338, 643-647 (2012).

4. Jeon, N. J. et al. Solvent engineering for high-performance inorganic-organic hybrid perovskite solar cells. Nat. Mater. 13, 897 (2014).

5. Jeon, N. J. et al. A fluorene-terminated hole-transporting material for highly efficient and stable perovskite solar cells. Nat. Energy 3, 682-689 (2018).

6. Green, M. A., Ho-Baillie, A. \& Snaith, H. J. The emergence of perovskite solar cells. Nat. Photon. 8, 506 (2014).

7. Grätzel, M. The light and shade of perovskite solar cells. Nat. Mater. 13, 838 (2014)

8. Ju, M. G. et al. Toward eco-friendly and stable perovskite materials for photovoltaics. Joule 2, 1231-1241 (2018)

9. Zong, Y. et al. Continuous grain-boundary functionalization for highefficiency perovskite solar cells with exceptional stability. Chem 4, 1404-1415 (2018).

10. Du, K. Z., Meng, W., Wang, X., Yan, Y. \& Mitzi, D. B. Bandgap engineering of lead-free double perovskite $\mathrm{Cs}_{2} \mathrm{AgBiBr}_{6}$ through trivalent metal alloying. Angew. Chem. Int. Ed. 56, 8158-8162 (2017).

11. Zhang, Z. et al. High-quality $\left(\mathrm{CH}_{3} \mathrm{NH}_{3}\right)_{3} \mathrm{Bi}_{2} \mathrm{I}_{9}$ film-based solar cells: pushing efficiency up to $1.64 \%$. J. Phys. Chem. Lett. 8, 4300-4307 (2017).

12. Wang M. et al. High-quality sequential-vapor-deposited $\mathrm{Cs}_{2} \mathrm{AgBiBr}_{6}$ thin films for lead-free perovskite solar cells. Solar RRL 2, 1800217 (2018).

13. Zuo, C. \& Ding, L. Lead-free perovskite materials $\left(\mathrm{NH}_{4}\right)_{3} \mathrm{Sb}_{2} \mathrm{I}_{\mathrm{x}} \mathrm{Br}_{9-\mathrm{x}}$. Angew Chem. Int. Ed. 56, 6528-6532 (2017).

14. Chen, M. et al. Cesium titanium(IV) bromide thin films based stable lead-free perovskite solar cells. Joule 2, 558-570 (2018).

15. Ju, M. G. et al. Earth-abundant nontoxic titanium(IV)-based vacancy-ordered double perovskite halides with tunable 1.0 to $1.8 \mathrm{eV}$ bandgaps for photovoltaic applications. ACS Energy Lett. 3, 297-304 (2018).

16. Krishnamoorthy, T. et al. Lead-free germanium iodide perovskite materials for photovoltaic applications. J. Mater. Chem. A 3, 23829-23832 (2015). 
17. Wang, N. et al. Heterojunction-depleted lead-free perovskite solar cells with coarse-grained B- $\gamma$-CsSnI ${ }_{3}$ thin films. Adv. Energy Mater. 6, 1601130 (2016).

18. Hao, F., Stoumpos, C. C., Cao, D. H., Chang, R. P. H. \& Kanatzidis, M. G. Lead-free solid-state organic-inorganic halide perovskite solar cells. Nat. Photon. 8, 489 (2014).

19. Shao, S. et al. Highly reproducible Sn-based hybrid perovskite solar cells with 9\% efficiency. Adv. Energy Mater. 8, 1702019 (2018).

20. Dang, Y. et al. Formation of hybrid perovskite tin iodide single crystals by topseeded solution growth. Angew. Chem. Int. Ed. 55, 3447-3450 (2016)

21. Zhou, Y. et al. Doping and alloying for improved perovskite solar cells. $J$. Mater. Chem. A 4, 17623-17635 (2016).

22. $\mathrm{Wu}$, B. et al. Long minority-carrier diffusion length and low surfacerecombination velocity in inorganic lead-free $\mathrm{CsSnI}_{3}$ perovskite crystal for solar cells. Adv. Funct. Mater. 27, 1604818 (2017).

23. Chung, I. et al. $\mathrm{CsSnI}_{3}$ : Semiconductor or metal? High electrical conductivity and strong near-infrared photoluminescence from a single material. High hole mobility and phase-transitions. J. Am. Chem. Soc. 134, 8579-8587 (2012).

24. Lee, S. J. et al. Fabrication of efficient formamidinium tin iodide perovskite solar cells through $\mathrm{SnF}_{2}$-pyrazine complex. J. Am. Chem. Soc. 138, 3974-3977 (2016).

25. Marshall, K. P., Walker, M., Walton, R. I. \& Hatton, R. A. Enhanced stability and efficiency in hole-transport-layer-free $\mathrm{CsSnI}_{3}$ perovskite photovoltaics. Nat. Ener. 1, 16178 (2016).

26. Song, T.-B., Yokoyama, T., Aramaki, S. \& Kanatzidis, M. G. Performance enhancement of lead-free tin-based perovskite solar cells with reducing atmosphere-assisted dispersible additive. ACS Energy Lett. 2, 897-903 (2017).

27. Zong, Y. et al. Homogenous alloys of formamidinium lead triiodide and cesium tin triiodide for efficient ideal-bandgap perovskite solar cells. Angew. Chem. Int. Ed. 56, 12658-12662 (2017).

28. Sabba, D. et al. Impact of anionic $\mathrm{Br}^{-}$substitution on open circuit voltage in lead-free perovskite $\left(\mathrm{CsSnI}_{3-\mathrm{x}} \mathrm{Br}_{\mathrm{x}}\right)$ solar cells. J. Phys. Chem. C. 119, 1763-1767 (2015).

29. Ju, M. G., Dai, J., Ma, L. \& Zeng, X. C. Lead-free mixed tin and germanium perovskites for photovoltaic application. J. Am. Chem. Soc. 139, 8038-8043 (2017).

30. Ito, N. et al. Mixed Sn-Ge perovskite for enhanced perovskite solar cell performance in air. J. Phys. Chem. Lett. 9, 1682-1688 (2018).

31. Nagane, S. et al. Lead-free perovskite semiconductors based on germanium-tin solid solutions: structural and optoelectronic properties. J. Phys. Chem. C. 122, 5940-5947 (2018).

32. Chen, M. et al. Light-driven overall water-splitting enabled by a photoDember effect realized on 3D plasmonic structures. ACS Nano 10, 6693-6701 (2016).

33. Mihailetchi, V. D., Wildeman, J. \& Blom, P. W. M. Space-charge limited photocurrent. Phys. Rev. Lett. 94, 126602 (2005).

34. Dong, Q. et al. Electron-hole diffusion lengths $>175 \mu \mathrm{m}$ in solution-grown CH3NH3PbI3 single crystals. Science 347, 967-970 (2015).

35. Shi, D. et al. Low trap-state density and long carrier diffusion in organolead trihalide perovskite single crystals. Science 347, 519-522 (2015).

36. Song, T.-B. et al. Importance of reducing vapor atmosphere in the fabrication of tin-based perovskite solar cells. J. Am. Chem. Soc. 139, 836-842 (2017).

37. Saliba, M. et al. Incorporation of rubidium cations into perovskite solar cells improves photovoltaic performance. Science 354, 206-209 (2016).
38. Huang, Z. et al. Suppressing the formation of $\mathrm{GeO}_{\mathrm{x}}$ by doping $\mathrm{Sn}$ into Ge to modulate the Schottky barrier height of metal/n-Ge contact. Appl. Phys. Exp. 9, 021301 (2016).

39. $\mathrm{Wu}, \mathrm{Y}$. H. et al. Comparison of Ge surface passivation between $\mathrm{SnGeO}_{\mathrm{x}}$ films formed by oxidation of $\mathrm{Sn} / \mathrm{Ge}$ and $\mathrm{SnGe}_{\mathrm{x}} / \mathrm{Ge}$ structures. IEEE Electr. Device Lett. 32, 611-613 (2011).

\section{Acknowledgements}

The work at Brown University and University of Nebraska-Lincoln (UNL) was funded by the US National Science Foundation (OIA-1538893). Computations were performed at UNL Holland Computing Center. L.K.O., Z.H., and Y.B.Q. acknowledge the funding support from the Energy Materials and Surface Sciences Unit of the Okinawa Institute o Science and Technology Graduate University, the OIST Proof of Concept (POC) Program, the OIST R\&D Cluster Research Program, and JSPS KAKENHI Grant Number JP18K05266. We thank Ms. Y. Zong for her experimental assistance.

\section{Author contributions}

M.C., Y. Zhou, N.P.P., M.-G.J., and X.C. Zeng conceived the idea. Y. Zhou and N.P.P. supervised the project. Y. Zhou and M.C. designed the experiments. M.C. performed the film fabrication, most of materials characterization, and device fabrication/testing. H.F.G. helped with the thermal evaporation of perovskites. Y. Zhang assisted with the device fabrication. L.K.O., Z.H., and Y.B.Q. conducted the XPS mapping. A.D.C. and R.L.G. performed the regular XPS measurements. M.-G.J. and X.C. Zeng performed the theoretical calculations. T.S. and D.P. helped with the optical characterization. Y. Zhou, M.C., and N.P.P. co-wrote the paper, with comments from all the other authors.

\section{Additional information}

Supplementary Information accompanies this paper at https://doi.org/10.1038/s41467018-07951-y.

Competing interests: The authors declare no competing interests.

Reprints and permission information is available online at http://npg.nature.com/ reprintsandpermissions/

Journal peer review information: Nature Communications thanks the anonymous reviewers for their contribution to the peer review of this work.

Publisher's note: Springer Nature remains neutral with regard to jurisdictional claims in published maps and institutional affiliations.

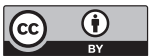

Open Access This article is licensed under a Creative Commons Attribution 4.0 International License, which permits use, sharing, adaptation, distribution and reproduction in any medium or format, as long as you give appropriate credit to the original author(s) and the source, provide a link to the Creative Commons license, and indicate if changes were made. The images or other third party material in this article are included in the article's Creative Commons license, unless indicated otherwise in a credit line to the material. If material is not included in the article's Creative Commons license and your intended use is not permitted by statutory regulation or exceeds the permitted use, you will need to obtain permission directly from the copyright holder. To view a copy of this license, visit http://creativecommons.org/ licenses/by/4.0/.

(C) The Author(s) 2019 